Article published in Asia-Pacific Journal of Teacher Education (2001), 29 (2), 187-196

\title{
Negotiating methodological dilemmas in a range of chilly climates - a story of pressures, principles and problems
}

\section{Lyn Yates}

(Address for correspondence:

Professor Lyn Yates, Faculty of Education, University of Technology, Sydney, PO Box 222 Lindfield NSW 2070. Lyn.yates@uts.edu.au. fax 029514 5620. Ph 029514 5230.)

Negotiating methodological dilemmas in a range of chilly climates - 


\title{
a story of pressures, principles and problems
}

\section{Lyn Yates}

\section{La Trobe University}

\begin{abstract}
This article discusses methodological, ethical and material issues related to the author's work on a qualitative, longitudinal research project, the 12 to 18 Project. It discusses the difficulty of balancing concerns about reactivity with concerns about obligations to the research subjects; the effects of the current Australian university funding regime on the shaping and conduct of research; and the difficulty of taking up particular research questions in certain political climates.
\end{abstract}

Five years ago, with Julie McLeod, I started a new longitudinal research project. Somewhat inspired by the British television and film series, $7 \mathrm{Up}$, and also by the Gillian Armstrong series of films about 3 Adelaide schoolgirls (beginning with Smokes and Lollies, then Fourteen's Good; Eighteen's Better; Bingo, Bridesmaids and Braces and last year's Not Fourteen Again), we decided to follow some girls and boys at four different Victorian schools through each year of their secondary schooling. Twice a year we interview them, often with their friends, and the aim is to build up a new picture of a number of things about young people and schooling in Australia today: what the development of gendered identity actually looks like now; how differences are created and maintained; how schooling interacts with individuals to create patterns of inequality; how identity, attitudes, and thinking about 
the future are developed over time within individual biographies as well as in more crosssectional or social patternings related to age or school or ethnicity or social class.

The project is still going on: the students are about to begin year 12; and a number of papers have been given and published discussing theoretical issues and emerging findings arising from the project. But there is also another story to be told, about the mundane and contextual pressures that have shaped the project from its very beginnings. It is a story about a political and financial context which makes some forms of research worth doing and others increasingly problematic; it is a story about researchers who try to do the right thing but can't avoid disappointing some of those involved; it is a story about wanting to acknowledge uncertainties but also to claim to be doing and saying something worthwhile. I've called the paper 'negotiating methodological dilemmas in a range of chilly climates ${ }^{1}$ because, as I want to show, there are a number of developments now which are somewhat unfriendly to the type of project we wanted to do in our longitudinal study, not just in Australian education politics and research funding, but also in the theories and traditions of we were working from, and also in relation to more personal and material pressures on what we as academics now need to do to survive.

\section{Tensions for feminist longitudinal research}

I'll begin with theory, and particularly feminist research. Feminist research has had a major impact in the education research field over the past two or three decades, and Australian research has been very much at the forefront of that. In some ways what Julie McLeod and I

\footnotetext{
${ }^{1}$ This article is a revised form of a paper initially given at Charles Sturt University in October 1997. I am grateful to Elizabeth Hatton, Bob Meyenn and Judith Parker for arranging the symposium for which this was originally written.
} 
were aiming to do in the 12 to 18 Project was to contribute a line of research (qualitative, longitudinal) different from the types of studies that other people were doing - a very traditional form of thinking up new projects. The problem was that in terms of feminist discussions about research methodology we were setting out to adopt an approach which in many ways was rather traditional - to go out twice a year and interview students. We were not aiming to develop a close relationship with the students; we were not aiming to give them a lot of say in where the research was going; we were not intending to give them a chance to comment on our transcripts or interpretations.(See (Yates \& McLeod, 1996, McLeod \& Yates, 1997, Yates, 1996, Yates, 1998) for more detailed discussions of these decisions.)

One major contribution that feminism has made to discussions of research methodology is to turn a new spotlight on the social relations of the researchers and the research subjects ('the personal is political'). It has asked questions about who benefits out of the research; who is being exploited; whose voice is being heard; whose questions are being pursued; whose interpretations rule, and how the gendered and other social experiences of the researchers and subjects are a factor in what emerges. I think these are extremely important questions.

Working with these questions, feminist researchers have often taken care to act collaboratively with those studied to define what is pursued (eg Mies, 1983; Stanley and Wise, 1983); they have been centrally concerned about reciprocity between researchers and researched (eg Fine, 1992); and reflexivity on the part of the researcher (Lather,1991). More recently, influenced by the work of Michel Foucault, they have intensively scrutinized the researcher's constructions and assumptions, to look sceptically at how they construct truths 
and exercise power (for example, a lot of the contributions to Luke and Gore, 1992, take this form, also Gore, 1993).

Of course feminism has not been a sole voice in these developments. In Education, many of the writers concerned with case study and with critical action research have raised similar themes; and in sociology and anthropology, the influence of Foucault and related writings has been so strong that it gave rise to the joke we quoted in an earlier paper:

Q: 'What does the postmodern ethnographer say to the interviewee?'

A: 'Enough about you! Now let's talk about me.'

So, where does this leave us and our project? Firstly, on the relationship we proposed to construct with the students in the study, we decided against attempting to build a close and strongly reciprocal relationship for a number of reasons. One was that in terms of our aims in this project, we did want to keep some focus on the processes going on in a world 'out there'; we wanted to avoid only studying the effects of our own intervention. Compared with the Seven Up series for example, where participants are shown their earlier tapes before each interview, and have talked about the big effect that being in the study has had on their lives, we wanted our project not to be a major factor in the lives of the students we studied.

That was our starting position, but there is no way of entirely avoiding the dilemmas identified by Ann Oakley that 'interviewing necessitates the manipulation of interviewees as objects of study/sources of data, but this can only be achieved via a certain amount of humane treatment' (Oakley, 1981, p.33) and that a longitudinal involvement in particular will tend to build a relationship between subject and interviewer, often beyond the one the latter intends. In our study, for the students, being selected for the study and coming out of 
class to do interviews twice a year, and being given opportunities to talk about yourself at regular intervals to a non-judgemental stranger, does have some inevitable impact, and this is something we try to observe and reflect on as we go on.

For some of the students in our study our presence appeared to offer some safety-valve opportunity for them to talk but not have to revisit that talk or see us again for another six months. In general, despite a low-key approach on our part, most students have become increasingly interested in the project and talk at much more length as we have gone on. However, in a couple of cases in relation to particular interviews, asking students to come and 'bring two friends' actually added to the stresses they were in at a particular point because they did not have two 'friends' at school at that point; or because their nominal friend was currently a source of anguish to them.

Again, though we were clear both explicitly in the initial negotiation with students and in our own minds, that our relationship with them was to be a limited and research-focussed one, not that of a pseudo-friend or proto-counsellor, these are matters of ongoing interpretation and degree, not neatly bounded. In two cases we have been concerned about a student's low self-image and negative self-evaluations and have felt it appropriate to comment positively to them about the things that we see they have achieved in the five years we have been talking to them. In another case, a student who is seriously depressed has asked us for the tape of a particular interview which he remembered as a very positive time 
for him, and we have complied with this request, though in general we do not want students to view the tapes until the final stage of the project. $^{2}$

In relation to exploring identity, it is true that dropping in twice a year and asking a series of fairly ordinary questions about how you see yourself, your memories of prep and grade 6, whether you think about the future, and so on; will be inevitably a limited or partial means of getting insight into the processes of students' development. But so will any other form of research. The issue is not avoided, for example, by having a more intimate and confessional series of conversations where a student is asked to reveal the truth about themselves at length. In either case the interviewee is constructing truths about themselves, relative to contexts - but in either case too we may 'find out' something about them from those situated discussions. (Maggie Maclure's (1993) work on 'mundane autobigraphy' is useful on these issues.) Moreover, in terms of what we are trying to investigate here, Harriet Bjerrum Nielsen (1996) makes a useful distinction between gendered identity (self-conscious views of self as male or female) and gendered subjectivity (the gendered background shape of our approaches to the world, which we might not consciously recognize as gendered). We are interested less in finding out what students would say directly to questions like 'what does it mean to you to be a girl, or a boy?' than in how gender is there as a background feature of how they answer other questions about their schooling, or their family, or their future.

So, that is why, for epistemological reasons (that is, in terms of what we wanted to 'find out'), we decided to have a relatively traditional form of research approach rather than a

\footnotetext{
${ }^{2}$ Although we do not talk to teachers about things that are said in the interviews, in this case we did indicate that we were concerned and checked that arrangements were being made for more professional sources of help for the student.
} 
more intimate and overtly reciprocal one. But what of the other issues raised in those feminist methodological debates: the ethical issue of who is benefiting and being exploited here; and the political issues of research as power?

Ethically, we feel that, in the school context at least, collaborative and action research has no necessary superiority to the type of research we outline here. In both cases, the researcher has an investment in the research which is different from that of the other participants. Although in other projects student participants may be encouraged to take a fuller part in steering the direction of a project, they are doing this within parameters and effects outside their direction. In our case our consideration of what we are doing to and for the students is mainly concerned to minimize the demands we make of them, as well as, of course, to keep our promises that they will not be identified or reported to others. Now in some cases students in fact would like to be named in our writings about the study, and it is true that this would allow them to gather greater recognition for their contribution, but it is not something we are willing to do, partly because doing this could be harmful to some of those involved, and partly because we want to keep a clear distinction that this is not a study about these particular individuals, but a study about young people, which draws on these students to do so. However, the issue of reciprocity, of how we respond to explicit and implicit demands from students, and of what type of opportunities we give them to 'speak back to' the study and to our own directions and interpretations, are ones that we are still thinking about and making decisions about as we go on further with the study.

In terms of the politics of what we are doing as researchers, in constructing our truths about the world, we agree with the recent directions in social theory and research methodology to look more seriously and sceptically and reflexively at this. However we think there is a 
problem about assuming that the implication of this is to turn everything into a wholesale discussion about the researcher themselves. Feminist research in particular is heavy with autobiographical reflection, and while there is a place for this, we need to be aware of the problem (signalled in the earlier joke) whereby researchers become fascinated only with themselves. So in this project, we are trying to think about the way in which our own personas and assumptions have formative effects on the research, but we want to keep clearly in our own minds that the point of this research is not to explore ourselves, but to contribute to questions about young people and their education.

To give a few examples of how we have tried to keep the focus on the young people, but also be reflexive about our presence and its impact, I will use ones we have discussed in other papers. In one case, in the early rounds of interviews we were asking students about what they thought they would be doing at 25 , and what they would like to be doing then. In one example, a girl from a wealthy background talked at length about how she would like to be a part-time barrister and a part-time journalist, and travel the world, and take a lot of photographs. And then she looked at us and paused, and began to talk about how she would really also love to go over to Somalia and spend time helping the people there. At a different school, with girls from a poor and rural background, the interview went like this:

[Int] What do you think your life will be like when you leave school? Do you think about that much?

(silence ... all three girls shake their heads)

[Int] What would you like to be doing Melanie? [names are changed]

[1st girl] Maybe babysitting ... and play for Australia in netball.

[2nd girl] Babysitting. 
[3rd girl] Same.

\section{[Int] What about when you're 25. Any ideas?}

[1st girl] (shakes her head)

[2nd girl] (taking on a serious expression) Help look after Brendan when he has asthma.[...]

[Int]What about if you could have a wish and do anything you really liked. What would you like to do when you're 25?

[2nd girl] Live with sister - the oldest one $-[\ldots$ ] in (nearest larger town)

[3rd girl] (who has virtually said nothing to this point in the interview)

Get a job.

(Yates \& McLeod, 1996)

Now in these examples, we might take the responses at face value and talk about the difference in aspirations from the two situations (barrister versus 'get a job' or 'babysitter'), or we might talk about how both examples show evidence for Carol Gilligan's arguments about girls' desire to balance relationship and autonomy in their future aspirations, but that it takes a different substantive form according to class opportunities. In other words, here, as elsewhere, the structuring of our study enables opportunities for comparison and contrast between girls by school, by age, by background. But we think it also adds to our understanding if we focus also on what is going on in the interview itself. In the first case the girls is not only comfortable with our present, and fluent, articulate and talkative; but she is self-monitoring of the face she is presenting to us - she pauses, looks at us, before adding the Somalia line to balance the themes of pleasure and success she initially gave us. In the second case, these girls are neither familiar with dealing with strangers like us, nor comfortable with that (discussed further in McLeod \& Yates, 1997). 
In another paper (Yates, 1997) I have considered our reading of our initial interviews where we asked the students to describe themselves and their friends. Here, we had found the boys' responses very interesting and unexpected, as compared with those from the girls. The boys talked far more about friendship and caring, and about future family life than we had envisaged. But equally, we realized that the girls too were presenting a varied picture - they talked about sporting success and careers as well as relationships. This led us to review our assumptions and the literature that in some senses had more concretely prepared us to see girls in differentiated ways but boys in more schematic ways.

In a third example (McLeod \& Yates, 1997), we considered a series of interviews where we asked students about dieting and the significance of appearance. Here we interpret what students say in terms of what discourses of inequality and gender they seem to be working with - but we also have to raise and consider the implications of the fact that the answers they give here are given to two female, older, professional interviewers, to understand that they might say other things in other contexts, and to think about why they think it is appropriate to say these things to us.

\section{The material effects of regimes of research funding}

A second macro-methodological issue facing educational researchers today is that different types of research may make a difference in the not-so-minor matter of whether we keep our jobs! I'll be coming back to the issue of topics, values and politics and how they enter in, in the final section of this paper. Here I want to consider funding in relation to forms of research; how funding considerations influence and constrain projects, and more specifically the issue of the emphasis now being placed on gaining ARC funding. The latter not only 
influences your conditions of work directly, in terms of what money you have available to purchase computers or travel and so on; but also indirectly, in that the institution in which you work is itself funded differentially according to the amounts researchers win from the ARC. So there is a lot of pressure these days not only to construct projects that will win competitive funding; but to construct projects that can cost a lot of money. This context has been an issue for the project I am discussing today.

First, this project represented a new form of work for me (and also for Julie McLeod). Before it, my work had been about directions in gender reform and feminist theory; about curriculum theory, about policy, and about theory and practice. It was work where I was basically working with ideas and with documentary materials - policies or published research. Before the 12 to 18 Project, except for a couple of minor in-house applications to support some students, I had never applied for a research grant, although I had been working in Education at La Trobe since 1977, had a respectable list of publications, was a relatively senior academic, and had even served on some national bodies responsible for distributing research and consultancy grants. Now, although there was some theoretical justification from my earlier work, to test out and build on that work in new ways, I was clearly also being spurred along by the knowledge that if I continued to work in ways that were not seen to cost money, then my university and faculty would be a loser.

I want to give you some examples of how the system is currently working, and then come back to some decisions we made about this project. The competitive funding model, both inside and outside universities, initially judges quality (albeit imperfectly, given some features of the refereeing system and the panel compositions), but it then conflates the dollars awarded with the hierarchy of quality. For example, I was on the non-sciences Small 
ARC panel within my university one year, and we considered a large number of applications from different researchers in different schools. The one that we eventually ranked number one was a philosopher. He was an internationally regarded figure and had a proposal that was ranked as outstanding, and was applying for some money for teaching relief. From memory, he applied for around \$8,000 (the maximum was $\$ 15,000$ ) and we granted him what he asked for. Down around number 10 on our list was a psychologist (we were actually ranking 105 applications, so this was still pretty high up). We did not rank this project as highly as the first one, but did think it was deserving of funding. This applicant had applied for $\$ 14999$. When we asked the psychology representative whether the researcher really needed this full amount, he explained that this area of work was a laboratory-based and ongoing project which could basically use as much money as they could get. So that researcher ended up getting more money than the philosopher. I know from experience of other committees that in other contexts, his record would seem as if he was rated more highly than the one we had in fact rated first, because he got more money, and similarly his school and faculty would be seen as more successful. In the distribution to universities the total money granted in large ARCs matters, not simply the number or proportion who have been successful.

How does this climate affect research? First of all, it means that much more time has to be spent putting in research applications, and often people are encouraged to put in a stream of new applications rather than ensure that they put proper energy into doing well the initial one. This is something that I have been resisting since taking on the current project, though it might be said that this is selfish in relation to what would benefit my School. Secondly, people are being encouraged to think about how to design a project that needs lots of money. Most of the applications I have been sent to review by the ARC were clearly designed with 
this in mind. They had people doing very large-scale research in different parts of the country, with multiple participants, and meeting with people all over the world. (My point is not that these were poor projects - many were excellent; my point is that the material realities of what is rewarded financially are leading the educational research field in a particular direction.)

Taking another aspect of the same problem, an eminent Australia researcher, Peter Fensham, commented in his address on being made a life member of AARE, that he was concerned about ARC proposals he kept getting to review, which aimed to do ethnographies, but in which the actual fieldwork was to be done by a research assistant. The point is that for most of the interpretive forms of research I am interested in, it is quite inappropriate to think that it can be done at second hand - but, unless you need to employ people, it's hard to build up your funding needs to a respectable amount. ${ }^{3}$

What Julie McLeod and I did in this project has been a compromise, though it has not been an entirely satisfactory one. Leaving aside these material pressures, we wanted this project in scope to be big enough to have some comparative possibilities and some weight in terms of our findings. That is, we wanted to look at some different types of schools, and to have the possibility both to think about gender in relation to different contexts of school, social class and ethnicity; and also to have students of similar background to enable some comparisons with like students. However we also wanted the study to be small enough to enable we ourselves to do all the interviewing and interpretation. We did include a request for a research assistant to manage the materials and budget (already in year five of the study, the

\footnotetext{
${ }^{3}$ And my experience is that requests for time-release (ie substitute teaching) for the researchers is treated much more critically than requests to employ others to do the research.
} 
video-tapes alone take up a cupboard which covers half of a wall; and the papers fill several filing cabinets), do some literature searching; make arrangements with schools and students for each new round of interviews (we ourselves did the original negotiations and discussions regarding permission); organize the typing of transcripts and the copying of tapes; and we also spend money on a transcript typist; on some equipment, some travel; a little teaching relief. However, although our application was ranked highly and we were awarded the threeyear grant the first time we applied; because we were clear that the central work was to be done by us, our budget was cut back quite a lot, and the money we are getting is not in the upper ranks of the large ARC amounts, which in turn affects infrastructure grants. (Equally, we were funded sufficiently to cover the essential needs of this project - so this is about the contextual issues of whether if one was being strategic one should avoid this type of qualitative work!)

The other problem these different issues have also raised for us relates to feminist issues about research teams, recognition and exploitation. Some initial collections on feminist research methodology (for example, Roberts, 1981) rightly noted the exploitation that was often part of the treatment of research assistants, typists, and graduate students: who does the work, who gets acknowledged, who benefits. Unlike many other projects we have not asked those we have employed as research assistants to carry out interviews or to provide interpretive input. This is partly because we have designed this as a project over time in which the continuity and closeness of reflection and design is part of its coherence. We thought that being clear about this with potential research assistants would avoid misunderstanding, and the fact that we wanted to do all the interviews and analysis ourselves would avoid appropriation of the intellectual labour of others. But the division of labour this approach introduces itself solidifies old hierarchies of mental and manual labour. We found 
that in practice no matter how clearly we describe the limits of the work we want the research assistants to do when we begin, as we go on, the fact that we are doing the interesting work in this project ourselves is rather disappointing to others who work on it - it makes that type of job less satisfying for those doing it, an administrative job rather than a 'research' job.

\section{Political climates and research today}

The final chilly climate I want to talk about is that of education politics and how this may affect the questions we pursue as well as the ways we need to present our results. As we all know, this is an era characterized by competition and privatization, by a lack of respect for 'public' institutions, and by a more directly political governance of education. Ministers more directly control education departments, and there is a large-scale pattern of issuing consultancies and research contracts to the researchers known to be very favourable to the policies of the day; and of directly punishing those who voice criticisms (both researchers and school principals).

I have had a very long-standing interest in questions about education inequality: what this looks like, how it is produced, how it might be mitigated. The 12 to 18 Project was designed, in part at least, to pursue further issues of what inequality looks like today (class in relation to gender, ethnicity and so on), and what different schools do in relation to this. The problem is however that in the current climate exposing how inequalities work may be at best irrelevant and at worse may contribute to the problem. As we saw in the current Minister's possible threat to reduce funding to schools doing less well in relation to literacy; the philosophy of governments quite widely is to look for and reward winners; not to respond to 
news about those who are losing by offering to help them. It is clearly a different climate from the heyday of inequalities work in the 1960s and 1970s.

Roger Woock makes a similar point in a review of four new books recently produced by a range of some of the leading Australian researchers who are concerned about such issues. On the one hand, it is clear that he thinks these books offer extremely good analyses of their various topics; on the other hand, he poses the question, who is reading these:

Who are these books written for? [...] here is the dilemma: few currently in a position of educational leadership running a school, a school system or a faculty of education are likely to read these books and if they do they would be very unlikely to assign or recommend them to their colleagues or students or indeed to take the analysis seriously. If they did, current policies and practices would need to be rethought from the ground up. We have in professions like education, nursing and youth work the dilemma of an excellent body of critical analysis making no discernible impact on the profession. [...] The power of economic rationalism and 'market forces' seems overwhelming.

(Woock, 1997, pp.151-2)

The point I am making then is that in relation to this aspect of my project, there are problems to be considered about how to write up findings and conclusions that extend beyond being careful about identifying students and schools and so on. There are problems of how to frame the discussion so that it does not have a further reproductive effect. 
But the coda to this story of pressures, principles and problems should be to note that the issues I have been raising in this paper - about relations with those we research, about the material constraints and political climate in which we work, about how to frame studies and interviews appropriately to the questions we are interested in - are ones that any project must consider, and ones to which there will never be unproblematic solutions. The point is, I think, to be as aware of these as we can be.

\section{Acknowledgements}

The first half of this paper draws substantially on a paper written jointly with Julie McLeod, (McLeod \& Yates, 1997) The project was initially seeded with a research grant from the Graduate School of Education at La Trobe University; it has subsequently been funded by the Australian Research Council, with support from Deakin University and the University of Technology, Sydney. Sera Arnold, Kathleen Orr, Jasmina Radulovic and Michelle Arrow have been the main research assistants in different years of the project, with further assistance on specific elements of the work by Geraldine Ditchburn, Chris Brew, Karen Halasa, Esther Faye and Malcolm Turnbull. 


\section{References}

FINE, M.(1992) Disruptive Voices: the Possibilities of Feminist Research, (Michigan, University of Michigan Press).

GORE, J. (1993), The Struggle for Pedgagogies, (New York, Routledge).

LATHER, P. (1991), Getting Smart: Feminist Research and Pedagogy With/in the Postmodern, (New York, Routledge).

LUKE, C. \& GORE, J. (Ed.) (1992) Feminisms and Critical Pedagogy, (New York, Routledge).

MACLURE, M. (1993), Mundane autobiography: some thoughts on self-talk in research contexts, British Journal of Sociology of Education, 14 (4), pp.373-384.

MCLEOD, J., \& YATES, L. (1997) Can we find out about girls and boys today, or must we just settle for talking about ourselves. Dilemmas of a feminist, qualitative longitudinal research project. Australian Education Researcher, 24 (3), pp.23 - 42.

MIES, M. (1983) Towards a methodology for feminist research, in G.BOWLES \& R.D.KLEIN (Ed), Theories of Women's Studies, (London, Routledge).

NIELSEN, H. B. (1996) The magic writing pad - on gender and identity work, Young (Nordic Journal of Youth Studies) 4 (3), pp.2-18.

OAKLEY, A. (1981) Interviewing women: a contradiction in terms, in H.ROBERTS, Doing Feminist Research, (London, Routledge).

ROBERTS, H.. (Ed.) (1981), Doing Feminist Research, (London, Routledge).

STANLEY, L. \& WISE, S. 1983), Breaking Out: Feminist Consciousness and Feminist Research, (London, Routledge).

WOOCK, R. (1997), Only connect: critical analysis and professional practice, Melbourne Studies in Education, 38 (1), pp.145-152. 
YATES, L. \& Mcleod, J. (1996), “And how would you describe yourself?” Researchers and researched in the first stages of a qualitative, longitudinal research project, Australian Journal of Education, 40 (1), pp.88-103.

YATES, L. (1996), How do we generate useful knowledge about young people?, Revisiting Pathways, Personal Issues and Public Participation, Youth Research Centre: University of Melbourne, pp.9-16.

YATES, L. (1997), Gender equity and the boys debate: What sort of challenge is it? British Journal of Sociology of Education, 18(3), pp.337 - 347.

YATES, L. (1998), Dreams of the future in an era of change: longitudinal qualitative research speaks back to policy studies, paper presented at the American Educational Research Association Conference, San Diego. 


\section{University Library}

\section{- M M N E R VA A gateway to Melbourne's research publications}

Minerva Access is the Institutional Repository of The University of Melbourne

Author/s:

Yates, Lyn

Title:

Negotiating methodological dilemmas in a range of chilly climates: a story of pressures, principles and problems

Date:

2001

\section{Citation:}

Yates, L. (2001). Negotiating methodological dilemmas in a range of chilly climates: a story of pressures, principles and problems. Asia-Pacific Journal of Teacher Education, 29(2), 187-196.

Publication Status:

Published

Persistent Link:

http://hdl.handle.net/11343/34735 